\title{
A construção do ethos nos discursos do Papa Francisco
}

Luis Henrique Boaventura Ernani Cesar de Freitas ${ }^{b}$

\section{Resumo}

Este trabalho objetiva investigar a construção de uma nova liderança na Igreja Católica sob a luz dos estudos da cenografia e ethos por Dominique Maingueneau (2008a, 2008b, 2008c, 2008d), a construção da imagem de si no discurso. A pesquisa se concentra em um infográfico do jornal Correio Braziliense, na entrevista do Papa Francisco concedida ao Padre Antonio Spadaro e publicada na revista Civiltà Cattolica, em setembro de 2013, e na Exortação Apostólica Evangelii Gaudium - A Alegria do Evangelho, publicada em novembro de 2013. Este estudo procura demonstrar que Bergoglio trabalha para constituir um ethos de humildade e abnegação que encontra força e legitimidade pelo contraste com a figura do pontífice emérito Joseph Ratzinger, seu antifiador, representante de um conjunto de valores no qual o católico atual não reconhece mais liderança. A pesquisa também pretende ilustrar o porquê de a reforma prometida com a sobrevinda de Bergoglio ao papado dificilmente corresponderia à reforma imaginada pela jovem comunidade católica no mundo. Será demonstrado que a mudança mais significativa dos dois primeiros anos do novo papa se deve ao tom de seu discurso, não a intenções de mudança em qualquer aspecto da doutrina.

Palavras-chave: análise do discurso, cenografia, ethos.

Recebido em 29 de janeiro de 2015 Aceito em 11 de agosto de 2015

\footnotetext{
a Doutorando em Letras na Universidade de Passo Fundo (UPF), luishboaventura@hotmail.com

b Professor permanente do Programa de Pós-graduação em Letras da UPF, nanicesar@terra.com.br
} 


\section{Introdução}

Os dias de ínterim entre a renúncia de Joseph Ratzinger e o conclave de Jorge Mario Bergoglio ratificaram uma urgência anunciada desde o final do século XX: a necessidade de reforma da Igreja Católica. Sabe-se na sagrada Cidade-Estado que os católicos contemporâneos, sobretudo os mais jovens, olham para revoluções mais recentes, como o Concílio Vaticano II, como se olha para uma gasta página de livro de história. Há uma demanda de atenção para tópicos do cotidiano, fatos da vida do católico típico, que veio sendo ignorada nos últimos anos com esforço comparável ao que se despenderia para atendê-la. O católico viu sua Igreja afastar-se gradativamente da sua vida e de suas convicções com o passar do tempo e passou a exigir de seu líder uma representação que espelhe suas necessidades. Questões como a união homoafetiva, o aborto, a ordenação de mulheres ao sacerdócio e pesquisas com células-tronco não podem mais morrer às margens do debate.

A constituição de uma liderança que traga essas questões à tona, capaz de afinar-se a linhas progressistas de pensamento sem repelir a ala ortodoxa da Igreja, é o grande desafio do Papa Francisco. Bergoglio fala na participação do gênero feminino em decisões importantes na Igreja, mas nega a ordenação de mulheres ao sacerdócio; não exclui o homossexual da evangelização, mas não equipara a união homoafetiva ao casamento; não demoniza a mulher que aborta, mas não aprova o aborto em hipótese alguma. A pesquisa intende evidenciar que a constituição de ethos e o modo de organização enunciativo que Bergoglio engendra servem a um fortalecimento de posição dentro de uma cenografia que lhe permita legitimidade para operar, no máximo, uma reforma política, e não doutrinária, na cúria da Igreja. Afinal, o Papa Francisco representa uma nova liderança na Igreja ou uma velha liderança apenas ajustada a novos liderados?

Neste artigo, formulamos a seguinte questão norteadora: Jorge Mario Bergoglio opõe o ethos prévio herdado de Joseph Ratzinger para constituir um novo ethos capaz de fortalecer a liderança da Igreja Católica. O objetivo é encontrar evidências desse procedimento através da análise das vestes do Papa Francisco, de sua entrevista à revista vaticanista Civiltà Cattolica e da Exortação Apostólica. 
Nosso marco teórico situa-se na concepção de ethos e cenografia desenvolvidos por Dominique Maingueneau (2008a, 2008b, 2008c, 2008d) no âmbito da análise do discurso, com algum complemento de Charaudeau (2006, 2010a, 2010b) e Emediato (2008). A pesquisa é descritiva e bibliográfica com abordagem qualitativa; o procedimento foi observacional, e o método, dedutivo. Compõem o corpus um infográfico publicado pelo Correio Braziliense em março de 2013, uma entrevista realizada pelo Padre Antonio Spadaro pela revista Civiltà Cattolica, publicada em setembro de 2013, e a Exortação Apostólica Evangelii Gaudium - A Alegria do Evangelho, publicada em novembro do mesmo ano.

Este artigo é dividido em "2. A cenografia do ethos e antiethos", que por sua vez se subdivide em "2.1 A noção de ethos em Maingueneau" e "2.2 Uma questão de cenografia", e "3. O velho e o novo na Santa Sé", dedicado à análise do corpus com base em Maingueneau, subdividido em "3.1 As vestes de um papa” e “3.2 Muda-se o tom, conserva-se o discurso".

\section{A cenografia do ethos e antiethos}

\subsection{A noção de ethos em Maingueneau}

Embora antiga, a noção de que toda tomada de palavra acusa a elaboração, deliberada ou involuntária, de uma imagem de si mesmo no discurso ganhou notável revisão por parte de Dominique Maingueneau (2008a, 2008b, 2008c, 2008d) em sua semântica global. Ruth Amossy (2008) destaca que a integração do termo "ethos" às ciências da linguagem tem seu registro primordial na teoria polifônica da enunciação de Oswald Ducrot, sendo negligenciado por Benveniste, Erwing Goffman e Kerbrat-Orecchioni, mas somente desenvolvido nos trabalhos de pragmática e análise do discurso de Maingueneau (2008a, 2008b, 2008c, 2008d). O linguista francês recorre ao conceito de ethos aristotélico para elaborar a construção da imagem de si no discurso como forma de influência do locutor sobre o parceiro.

Maingueneau (2008c, p. 64) toma impulso na Retórica Aristotélica e apresenta sua perspectiva do ethos ao avançar além do quadro de argumentação para atingir o "processo mais geral da adesão dos sujeitos a determinado posicionamento". Maingueneau (2008c) lembra que Bakhtin já falava em "tom" 
em seus trabalhos; o ethos é a "voz" que perpassa o texto, uma voz que fala ao interlocutor em uma frequência paralela; assim é possível que ambos, tom e texto, digam coisas completamente diferentes ao mesmo tempo: "o discurso, por meio dos enunciados, produz um espaço onde se desdobra uma voz que lhe é própria. Dessa maneira, inicia-se um modo de abordar o texto que nele encontra uma oralidade, uma voz que lhe é constitutiva" (LAGO, 2008).

A projeção do ethos envolve a exposição de uma vocalidade que avalize o enunciador e seu discurso com uma chancela positiva. A produção dessa autoimagem positiva se opera, para Aristóteles, na intervenção de três qualidades fundamentais (EGGS, 2008a):

1. Prudência (phronesis), da ordem do logos;

2. Virtude (areté), da ordem do ethos;

3. Benevolência (eunoia), da ordem do pathos.

A Retórica de Aristóteles resgatada por Maingueneau trata do ethos percebido pelo público, não do ethos característico de um indivíduo ou grupo. A projeção do ethos obedece a uma lógica especular em seu processo, conforme afirma Maingueneau (2008c, p. 58), “a persuasão só é obtida se o auditório constatar no orador o mesmo ethos que vê em si mesmo". Princípio similar ocorre em relação à noção de virtude, relativizada em cenas de enunciação diferentes, com públicos diferentes. "Como virtude não é considerada em todos os lugares nem por todas as pessoas da mesma maneira, é em função de seu auditório que o orador construirá uma imagem de si conforme o que é considerado como virtude" (MAINGUENEAU, 2008c, p. 58).

Pesa sobre o ethos o papel de afiançar ("fiador", como veremos a seguir) o que é dito pelo indivíduo independentemente da integridade de suas palavras; isto significa que o sujeito pode empreender mecanismos (através de um determinado tom de voz, de um determinado conjunto de gestos e de certa forma de se vestir) que tanto podem apenas reforçar a sinceridade de seu discurso quanto ajudar a "vender", ou seja, a tornar crível e legítimo um discurso mentiroso ou não de todo verdadeiro, procedimento notável no âmbito dos discursos políticos. Charaudeau (2006) chama este processo de "parecer verdadeiro" como uma "estratégia de sedução" à 
qual o linguista francês conecta a própria fundação da política e como ela funciona. "Todo político sabe que lhe é impossível dizer tudo, a todo momento, e dizer as coisas exatamente como ele as pensa ou concebe, pois suas palavras não devem atrapalhar sua ação".(CHARAUDEAU, 2006, p. 204)

Em termos de ethos, é menos relevante o caráter verdadeiro do sujeito em relação ao seu caráter aparente, percebido pelo público ao qual se dirige. Conforme ilustra Barthes, mencionado por Maingueneau (2008a, p. 13, grifo do autor), "são os traços de caráter que o orador deve mostrar ao auditório (pouco importa a sinceridade) para dar boa impressão [...] O orador enuncia uma informação e, ao mesmo tempo, diz: eu sou aquilo, não aquilo lá". Contudo, este caráter aparente não entra em funcionamento apenas do momento da enunciação do discurso em diante, do mesmo modo que, ao ouvir um político ou uma liderança religiosa discursar, não processamos suas palavras como se o ouvíssemos pela primeira vez. Há uma base de informações previamente estabelecidas a partir da qual o público começa ao receber um discurso, como o partido que determinado político integra, a religião de determinado líder, sua história de atuação, suas ações no passado, gestos que ajudaram a formar uma opinião preliminar em relação ao locutor do discurso que está para ser enunciado. Maingueneau (2008b) decompõe essas diferenças em duas formas de ethos:

- Ethos pré-discursivo: a opinião que o destinatário possui do enunciador antes mesmo que ele comece a falar. No caso de um discurso que parte de um porta-voz da Igreja Católica, há um ethos prévio marcante que se desprende da memória coletiva recuperada a respeito dessa instituição. De acordo com Maingueneau (2008b, p. 71), "o simples fato de que um texto pertence a um gênero de discurso ou a um certo posicionamento ideológico induz expectativas em matéria de ethos".

- Ethos discursivo: o ethos que se constrói na efetividade do discurso. Conforme Ducrot, mencionado por Maingueneau (2008a, p. 71), “'trata-se] da aparência que lhe confere a fluência, a entonação, calorosa ou severa, a escolha das palavras, dos argumentos...".

O ethos pré-discursivo e o ethos discursivo entram em jogo no âmbito do discurso enquanto mise-en-scène, enquanto forma de encenação. "Não podemos, pois, contentar-nos, 
como a retórica tradicional, em fazer do ethos um meio de persuasão: ele é parte constitutiva da cena de enunciação [...]" (MAINGUENEAU, 2008b, p. 75). Por "cena de enunciação", Maingueneau (2008c) entende três tipos de cenas que a compõem:

- Cena englobante: atribui ao discurso um estatuto pragmático, integrando-o em um tipo: publicitário, administrativo, filosófico...

- Cena genérica: a do contrato associado a um gênero ou subgênero do discurso: o editorial, o sermão, o guia turístico, a consulta médica...

- Cenografia: não é imposta pelo gênero, mas construída pelo próprio texto.

Conforme Maingueneau (2008c, p. 70), "por meio do ethos, o destinatário está convocado a um lugar, inscrito na cena de enunciação que o texto implica". O corpus deste trabalho é composto de uma entrevista a um jornal do Vaticano e da Exortação Apostólica intitulada Evangelii Gaudium - A Alegria do Evangelho. Ambos têm em sua cena englobante o discurso do tipo religioso; como cena genérica, a entrevista e o documento pontifício oficial. Resta pendente, portanto, a análise da cenografia.

\subsection{Uma questão de cenografia}

Maingueneau (2008b, p. 76) explica que a adoção do termo cenografia se deve ao seu "duplo valor: (1) Acrescentando a noção teatral de 'cena' à de -grafia, da 'inscrição' [...] (2) consideramos o desenvolvimento da enunciação como a instauração progressiva de seu próprio dispositivo de fala". Isto significa que a lógica da cenografia costurada por Maingueneau diz respeito a um sistema que deve, ao mesmo tempo, outorgar o discurso que o constitui e por ele ser outorgado. Trata-se, como define o linguista, de um processo de enlaçamento.

Desde sua emergência, a fala é carregada de certo $e$ thos, que, de fato, se valida progressivamente por meio da própria enunciação. A cenografia é, assim, ao mesmo tempo, aquilo de onde vem o discurso e aquilo que esse discurso engendra: ela legitima um enunciado que, por sua vez, deve legitimá-la, deve estabelecer que essa cena da qual vem a palavra é precisamente a cena requerida para enunciar nessa circunstância. (MAINGUENEAU, 2008b, p. 71, grifo do autor) 
Constitui-se na cenografia o tabuleiro deste jogo de posições entre locutor e alocutário. Charaudeau (2010b, p. 60, grifo do autor), que divide com Maingueneau estreita paridade teórica, defende que "falar é também organizar a descrição do mundo que propomos/impomos ao outro". Os modos de organização do discurso de que nos fala Charaudeau (2006, 2010a, 2010b) são definidos conforme a finalidade do ato de comunicação. São quatro os modos de organização discursiva: enunciativo, descritivo, narrativo e argumentativo, de que modo que o primeiro (enunciativo) é dominante e opera sobre os demais com base em três funções distintas: alocutiva (estabelece uma relação de influência em relação ao interlocutor), elocutiva (revela o ponto de vista do locutor em relação ao mundo) e delocutiva (retoma a fala de um terceiro ao mesmo tempo em que se apaga do seu próprio ato de comunicação).

O modo enunciativo (segmentado nessas três funções), desta forma, tem como papel primário estabelecer a posição do locutor em relação ao interlocutor, em relação a terceiros e em relação a si mesmo, o que resulta, segundo Charaudeau (2010a, p. 74), na construção de um aparelho enunciativo; em função disso, ele intervém na encenação de cada um dos demais modos. O corpus de análise demonstrará um uso proeminente do modo de organização enunciativo com função de base alocutiva (relação de influência) por Jorge Mario Bergoglio, um jogo de posições em que o uso de modelos e mecanismos para empreender legitimidade e credibilidade coloca as figuras do fiador e antifiador no centro da cena.

Ao analisar o sermão como cena de enunciação, Maingueneau (2008d, p. 201) define assim os discursos de ordem religiosa: "o sermão, assim como qualquer pregação religiosa, situa-se na órbita dos 'discursos constituintes', ou seja, dos discursos [...] que servem de 'fiadores' para outros discursos". Os conceitos de fiador e antifiador são elementares para entender o processo de consolidação de liderança pela qual passa o Papa Francisco.

Conquistar a adesão do público ao discurso do enunciador envolve projetar um ethos que, além de inspirar uma relação empática entre as partes, crie as condições para que o público possa não apenas compreender, mas também participar do mundo particular de conceitos e de ideias que está sendo engendrado pelo discurso. Para tanto, é preciso haver 
a incorporação pela qual, como coloca Maingueneau (2008c, p. 65), "o destinatário em posição de intérprete [...] se apropria desse ethos". Todo discurso, seja oral ou escrito, possui uma vocalidade que permite relacioná-lo a uma fonte enunciativa (MAINGUENEAU, 2008b). A vocalidade subscrita em cada discurso corporifica o enunciador, dando forma a um "fiador" que atesta o que é dito. Atribui-se ao fiador um "caráter" (feixe de traços psicológicos) e uma "corporalidade" (compleição física e modo de se vestir). O destinatário se apropria do ethos (forma de mover-se no espaço social do fiador) através do que Maingueneau (2008b) chama de incorporação. Como posto pelo linguista, essa incorporação atua em três registros indissociáveis.

- A enunciação do texto confere uma coporalidade ao fiador, ela lhe dá um corpo.

- O co-enunciador incorpora, assimila um conjunto de esquemas que correspondem à maneira específica de relacionar-se com o mundo, habitando seu próprio corpo.

- Essas duas primeiras incorporações permitem a constituição de um corpo, da comunidade imaginária dos que aderem a um mesmo discurso. (MAINGUENEAU, 2008a, p. 73)

O espaço de argumentos, ideias e linhas de raciocínio construído pelo discurso é chamado de "mundo ético" por Maingueneau (2008c), um mundo ao qual o enunciador deve conceder acesso no papel de "fiador", cuja responsabilidade é atestar o que é enunciado. Como o fiador está relacionado a uma dinâmica corporal, o co-enunciador não decodifica o sentido, mas participa "fisicamente" deste mundo acessado por intermédio do fiador.O fiador é moldado de acordo com um caráter e uma corporalidade. “O caráter corresponde a um feixe de traços psicológicos. Quanto à corporalidade, ela é associada a uma compleição física e a uma forma de se vestir" (MAINGUENEAU, 2008c, p. 65).No caso de um líder religioso, portanto, o fiador é dado em sua maior parte previamente (ethos pré-discursivo): um padre tem no seu "título", na posição que ocupa, um caráter validado para a comunidade à qual se dirige, o que é reforçado por sua compleição física, as vestes e a pompa de que a Igreja Católica se vale e que o cercam, garantindo uma corporalidade e uma posição de fiador ideal ao mundo que ele dá acesso (da espiritualidade, da doutrina, do 
conjunto de regras que guiam a fé cristã). Partindo deste ethos prévio, cabe ao locutor instituir o ethos discursivo através da forma como enuncia seu discurso a partir do léxico escolhido, do tom e volume de voz, do conjunto de gestos.

Da mesma forma que o fiador utiliza-se de um ethos para validar seu discurso, para fazer adentrar a um mundo em que suas palavras são pertinentes, é possível que o enunciador se utilize de um antimodelo para contrapor um modelo que se quer validar, um antifiador para acentuar a pertinência do fiador que se engendra para cativar ("capturar") o público. Maingueneau (2008b) trata de uma cena a se contrapor como "cena validada", ou seja, já instalada na memória coletiva, compartilhada pelos membros de uma comunidade (como a comunidade católica, como o eleitorado de um país). Emediato (2008, p. 90) chama este tipo de validação de "pré-validação nas situações de comunicação monolocutivas, como é o caso das mídias". Assim, em uma propaganda eleitoral, um candidato da oposição pode usar um cenário atual de crise como antimodelo do cenário que pretende implementar em seu mandato, estabelecendo no candidato da situação seu antifiador.

No caso do Papa Francisco, há uma oposição imediata com relação ao Papa Bento XVI sinalizada pelo próprio conclave de 2013 e reforçada pela repercussão nas mídias e pelo debate entre teólogos e vaticanistas a respeito do significado de tal escolha. Como veremos, o discurso de Bergoglio se fortalece ao estabelecer em Ratzinger seu antifiador.

\section{O velho e o novo na Santa Sé}

O posicionamento de Bergoglio e sua atuação junto à opinião pública ilustram constantemente a recombinação entre o que Maingueneau (2008b) chama de ethos prévio e ethos discursivo; neste caso, em especial, pudemos verificar uma cenografia que envolve a afirmação de um ethos sobre o apoio de um antiethos, e a corporificação de um fiador pelo espelho de um antifiador definido sob o modo de organização de discurso enunciativo.

Quando tratamos de uma instituição como a Igreja Católica, deve-se esperar uma negociação contínua com a memória coletiva. O discurso religioso se projeta de seu misto ancestral de dogmas, preceitos e convicções, toma 
discretamente um pouco de ar na superfície, e para ele retorna igual ou não diferente o suficiente para alterá-lo. No caso da atuação de Bergoglio, qualquer diferença mais sensível de tom e de abordagem de determinados tópicos, matéria do presente artigo, servirá tão somente ao propósito de reforço do discurso.

O modo como a Igreja Católica atualiza seu discurso sem alterá-lo ao longo dos anos é um fenômeno digno de atenção, sobretudo pela maneira como o faz: o dado buscado para qualquer mudança de tom sempre esteve previamente disponível no próprio discurso, ainda que sob um arranjo diferente ou disposto em uma forma menos pregnante. Os hábitos franciscanos de Bergoglio, por exemplo, vão de encontro aos de Ratzinger, mas retomam ideias de humildade e abnegaçãodo próprio fundador da religião cristã, assim como os discursos ecumênico e de integração da mulher à Igreja não constituem novidade - estão arquivados na fala bíblica de Cristo. Vaticanistas, teólogos e jornalistas especializados sabem que não devem esperar mudanças. Em julho de 2013, reportagem de Carol Glatz publicada no site Catholic News Service ouviu o cardeal Walther Casper a respeito do perfil de Jorge Mario Bergoglio:

Entre ele e Bento XVI, há continuidade na doutrina", disse. O Papa Francisco "não vai mudar nada no celibato dos padres e não vai abrir às ordenações das mulheres" nem promover outras questões "progressistas" que não fazem parte do ensino da Igreja. O Papa Francisco "não é um conservador nem um progressista. Ele quer uma Igreja pobre e dos pobres", e está ciente de que uma grande parte do mundo vive na extrema pobreza, disse o cardeal [Kasper]. (GLATZ, 2013)

Está bastante pacificado que mudanças de doutrina não ocorrerão; nosso papel, contudo, é analisar o porquê da projeção de um ethos que abre espaço para uma miragem de mudança. O processo empregado por Bergoglio diz respeito à seleção de uma cena para servir-lhe de modelo e outra para ser usada como antimodelo, base de alavanca. De acordo com Maingueneau (2008b, p. 80-81):

O ethos dito, além da figura do fiador e do antifiador, pode também incidir sobre o conjunto de uma cena de fala, apresentada como um modelo ou um antimodelo da cena de discurso. Tal cena de fala pode ser chamada de cena validada, em que "validada" significa "já instalada na memória coletiva", seja como antimodelo, seja como modelo valorizado 
[...]. O repertório das cenas disponíveis varia de acordo com o grupo visado pelos discursos. Uma comunidade de convicção forte (uma seita religiosa, uma escola filosófica...) possui sua memória própria.

Como novo papa, Bergoglio precisa manobrar não apenas com o modelo há muito estabelecido (ethos prévio de uma milenar Igreja Católica), mas também com a versão mais recente deste mesmo modelo, deixada a ele de herança pelo papa que substitui, Joseph Ratzinger. Como aponta Emediato (2008a, p. 90), "a validação é o suporte de todo poder no discurso e a fonte de energia que assegura o seu prosseguimento".

Nos primeiros dias que sucederam o conclave, a imprensa romana, especialista nos assuntos do Vaticano, ainda procurava desfazer-se da surpresa e entender como o então arcebispo da distante e, por demais, não-europeia Buenos Aires, que sequer figurava entre os papabili especulados na Itália, ascendia ao posto de líder máximo da Igreja Católica com uma soma tão espetacular de votos: "mais de 90" dos 115 possíveis ${ }^{1}$. Andrea Tornielli (2013), por exemplo, vaticanista do jornal La Stampa, chamou o fenômeno de "Efeito Ratzinger". Antonietta Calabrò (2013), do jornal Corriere della Serra, afirma que houve um acordo entre os homens da Cúria e os cardeais americanos para que se tivesse, "finalmente, o papa das Américas". A distância entre Ratzinger e Bergoglio, figuras tão imediata e facilmente opostas em qualquer exercício de análise, foi decisiva para a eleição do argentino.

Vantagem de Bergoglio no conclave, a oposição entre ele e Ratzinger é sua principal aliada nos processos de renovação da imagem da Igreja e de injeção de frescor que os arfados pulmões do catolicismo há muito esperam. O ethos de Bergoglio se apoia no antiethos Ratzinger e na porção da Igreja que o alemão representa. Como o mais ecumênico dos últimos papas, o objetivo declarado de Bergoglio é unificar a Igreja e abraçar a todos aqueles dispostos a crer que a promessa de salvação é possível através de Cristo. Nesta mudança de tom de uma Igreja inflexível para outra, mais aberta, Bergoglio faz-se fiador de um "novo" catolicismo para o qual todos estão convidados. Sua potência como fiador deste mundo ético encontra base em

1 De acordo com Maria Antonietta Calabrò (2013), vaticanista do jornal Corriere della Serra. um antifiador, guardião do mundo discursivo que se está em vias de deixar e que vem perdendo a simpatia (sobretudo dos católicos mais jovens) nas últimas décadas. 


\subsection{As vestes de um papa}

A primeira mudança notada em Bergoglio foram suas vestes, compleição física constitutiva de uma certa corporalidade (MAINGUENEAU, 2008b) que se pretende elaborar na construção da imagem de si no discurso. A ideia de fortalecimento do catolicismo em que acreditava Ratzinger envolvia a recuperação de velhos ritos e de acessórios há muito esquecidos por seus antecessores, como chapéus, capas e toda sorte de metais nobres. Há de se recordar, por exemplo, a polêmica envolvendo a procedência dos "sapatos vermelhos do papa", que jornais garantiam ser da grife italiana Prada ${ }^{2}$.

Como já dito, as fontes das mudanças de discurso que de tempos em tempos empreende a Igreja sempre estiveram disponíveis previamente no seu próprio discurso. A noção de renovação de Ratzinger buscava fortaleza no passado, especificamente nos anos mais opulentos do catolicismo. Bergoglio volta mais longe e resgata os hábitos modestos presentes nas fibras mais antigas da palavra cristã. $\mathrm{O}$ jornal Correio Braziliense ilustrou as diferenças entre ambos ao analisar a vestimenta de Bergoglio em seus primeiros dias como papa:

Figura 1 - "Distante da ostentação"

2 Posteriormente, um artigo do L'Osservatore Romano atribuiu a confecção dos mocassins, vermelhos para representar o sangue de todos os que morreram por Cristo, a um imigrante peruano dono de uma pequena loja próximo à Praça de São Pedro.

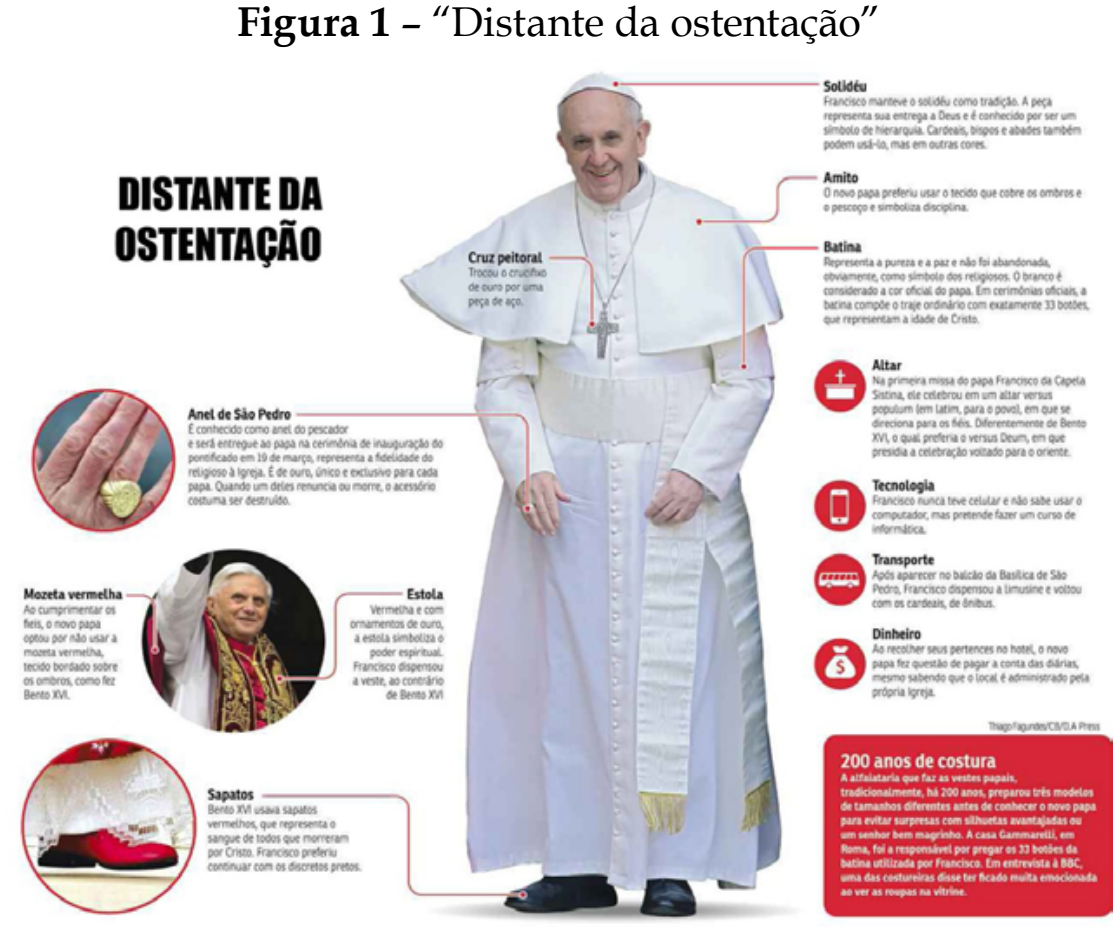

Fonte: (Correio Braziliense, 2013) 
O título do infográfico do jornal deixa claro que a estratégia é bem-sucedida: "distante da ostentação". Resta saber, é claro, o que exatamente se pretendia ostentar (que ethos projetar). Em 2007, a revista americana Esquire, um dos mais zelados emblemas da moda mundial, deu a Ratzinger o título de "melhor portador de acessórios" em razão de peças como o Cappello Romano e o gorro Camauro. Não se pode medir exatamente o quanto a postura de Bergoglio vai, na prática, de encontro à de Ratzinger quando, em 2013, a mesma Esquire afirma que o Papa Francisco é o "homem mais bem vestido do ano": ambos ethé diferentes projetados e bem assimilados pela imprensa mundial, cada qual com sua mensagem, cada qual com a missão de engendrar uma cena de discurso que melhor sirva à mise-en-scène proposta por seu enunciador. Conforme Maingueneau (2008b, p. 73),

A qualidade do ethos remete, com efeito, à figura desse fiador que, mediante sua fala, será uma identidade compatível com o mundo que se supõe que ele faz surgir em seu enunciado. Paradoxo constitutivo: é por seu próprio enunciado que o fiador deve legitimar sua maneira de dizer.

O mundo ético ao qual o Papa Francisco, enquanto fiador, pretende dar acesso é um mundo que pressupõe humildade, simplicidade, resignação, em contraste a um modelo de catolicismo propagado por seu antecessor e que não fazia mais do que sofrer resistência. Assim, Bergoglio projeta o fiador de um papa humilde, de vestes simples,de comportamento público humilde (seu contato corporal com o povo em sua passagem pelo Brasil, por exemplo), que se fortalece, sobretudo, pelo contraste com o modus operandi de Ratzinger e com a noção geral de que a Igreja Católica, apesar de pregar ideais de frugalidade, sempre esteve coberta de jóias.

\subsection{Muda-se o tom, conserva-se o discurso}

Algumas declarações de Bergoglio ao longo de seus dois primeiros anos de papado chamaram atenção como possíveis sinais de mudança de alguns dos pontos mais delicados da doutrina católica, como o sacerdócio reservado aos homens e o casamento homossexual. É preciso ter presente, contudo, a diferença entre os canais de propagação para os quais cada declaração é dirigida. A entrevista concedida a jornalistas 
credenciados no avião que o levou do Brasil de volta a Roma, em julho de 2013, talvez seja o mais representativo desses exemplos: respondendo a uma pergunta da repórter brasileira Ilze Scamparini ("como vai enfrentar o lobby gay?"), Bergoglio (2013c) afirmou: "se uma pessoa é gay e procura Jesus, e tem boa vontade, quem sou eu para julgá-la? O catecismo diz que não se deve marginalizar essas pessoas, devem ser integradas à sociedade. Devemos ser irmãos". No mesmo avião, confrontado com a participação da mulher na Igreja, Bergoglio (2013c) disse: "Pensem que Nossa Senhora é mais importante que os apóstolos. A Igreja é feminina, é mãe. Não fizemos ainda uma profunda teologia da mulher".

Fica clara a organização do discurso empregada sob o modo enunciativo com função de base alocutiva, ou seja, em que se estabelece influência sobre o interlocutor. Tal jogo de posições parte de um estado de desequilíbrio quando se considera os papéis previamente atribuídos aos atores do discurso. O locutor (Jorge Mario Bergoglio, instituído na condição de papa) age sobre o interlocutor, atribui-lhe papéis linguageiros e se enuncia em relação a ele de dois modos: ocupando uma posição de superioridade ou uma posição de inferioridade. No caso, a posição de superioridade faz parte da memória coletiva do catolicismo (do líder religioso sobre seus fiéis liderados). Esta relação de influência toma forma (inclusive física, com participação material no mundo, como vimos anteriormente) com a projeção do ethos.

O ethos que Bergoglio projeta é o de um líder aberto a mudanças, simpático a novos ares, exatamente o tipo de líder que os católicos não viam em Ratzinger e que exigiam já há alguns anos do Vaticano. Contudo, um líder realmente disposto à mudança, ou seja, a revoluções de fato na doutrina, improváveis mesmo para os católicos mais progressistas, incorreria no risco de corroer a base conservadora da Igreja e cindir a religião mais praticada no mundo. Na figura do Papa, de "mediador autorizado da palavra de Deus", Bergoglio já faz as vezes de "fiador do sentido autorizado pela Tradição" (MAINGUENEAU, 2008d, p. 206), dado impresso em seu ethos pré-discursivo. Para além deste fiador herdado, Bergoglio deve investir no ethos discursivo cujo fiador dará acesso a um mundo ético em que se está disposto a discutir, a "abraçar" questões 
antes intocadas, utilizando como antifiador a figura do papa inflexível e fechado a este tipo de diálogo, ao mesmo tempo em que não toma ações demasiado bruscas que poderiam assustar os católicos conservadores.Conforme Maingueneau (2008b, p. 79), “de acordo com o processo de 'enlaçamento paradoxal' já evocado, o leitor que o ethos 'incorpora' de imediato à cenografia adere progressivamente ao mundo que exige essa cenografia e nenhuma outra". Este procedimento é notável ao se analisar a entrevista de Bergoglio ao Padre Antonio Spadaro e ao revisar sua primeira Exortação Apostólica, dois documentos em que tais assuntos poderiam (deveriam) ter sido aprofundados, em contraste com declarações eventuais que rendem manchetes no ocidente.

O tema da participação da mulher na Igreja, delicado por uma série de razões, desde a queima de mulheres como bruxas na Santa Inquisição até as mais recentes transformações feministas das décadas de 1960 e 1970, ganhou menção na Exortação Apostólica:

As reivindicações dos legítimos direitos das mulheres, a partir da firme convicção de que homens e mulheres têm a mesma dignidade, colocam à Igreja questões profundas que a desafiam e não se podem iludir superficialmente. $\mathbf{O}$ sacerdócio reservado aos homens, como sinal de Cristo Esposo que Se entrega na Eucaristia, é uma questão que não se põe em discussão, mas pode tornar-se particularmente controversa se se identifica demasiado a potestade sacramental com o poder. (BERGOGLIO, 2013a, grifo nosso)

Como dito explicitamente pelo Papa, a possibilidade do sacerdócio investido às mulheres não está posto em discussão. Bergoglio está aberto às declarações leves, pouco ou nada comprometedoras, a respeito da suposta importância da mulher na Igreja, do seu papel central em sua constituição (Nossa Senhora acima dos apóstolos, como afirmou), mas tais declarações, é claro, jamais evoluem a um nível de compromisso com a mudança, de um sinal válido de que algum esforço de fato será empreendido. Basta que o ethos projetado cumpra seu papel: um papa mais aberto a questões antes indiscutíveis, agregando a simpatia dos católicos mais progressistas sem afligir os conservadores.

A questão da homossexualidade é posta tanto na Exortação Apostólica quanto na entrevista à Civiltà Cattolica. Convém analisar primeiro a resposta da entrevista: 
Pergunta (Spadaro): Penso nos divorciado s recasados, casais homossexuais, outras situações difíceis. Como fazer uma pastoral missionária nestes casos? Em que insistir? $\mathrm{O}$ Papa faz sinal de ter compreendido o que pretendo dizer e responde.

Resposta: [...] Uma vez uma pessoa, de modo provocatório, perguntou-me se aprovava a homossexualidade. Eu, então, respondi-lhe com uma outra pergunta: “Diz-me: Deus, quando olha para uma pessoa homossexual, aprova a sua existência com afeto ou rejeita-a, condenando-a?" É necessário sempre considerar a pessoa. Aqui entramos no mistério do homem. Na vida, Deus acompanha as pessoas e nós devemos acompanhá-las a partir da sua condição. É preciso acompanhar com misericórdia. Quando isto acontece, o Espírito Santo inspira o sacerdote a dizer a coisa mais apropriada". (BERGOGLIO, 2013b, grifos nossos)

É notável o modo como Bergoglio se refere ao homossexual através do léxico que seleciona e do tom condescendente que utiliza, denunciando um ethos que não se tinha a intenção de mostrar. "Acompanhá-las a partir de sua condição", "acompanhar com misericórdia" e "quando isso acontece" denota o tratamento a um desafortunado, alguém acometido ("acontece") por algum infortúnio, alguém aleijado socialmente por sua "condição" e que portanto inspira cuidados, que desperta sentimentos como a piedade, a "misericórdia". Deste momento em diante, Bergoglio abstém-se de uma orientação oficial e prefere crer, como diz, na inspiração concedida pelo Espírito Santo ao sacerdote no momento apropriado.

É certo que, diante dessa cenografia, o católico homossexual, ou o jovem ainda incerto quanto à sua religião e que busca representatividade ou acolhida em alguma doutrina que espelhe suas convicções, não identifica nessa declaração um discurso capaz de sinalizar mudanças. Os indivíduos excluídos da comunidade católica não buscam mero acolhimento, buscam aceitação, o que significa respeito quanto à totalidade de características que os constituem enquanto indivíduos, não referência a algumas dessas características como se representassem falhas de caráter ou acidentes genéticos. Mas ainda que esta postura esteja distante daquela que este indivíduo idealizaria, ela é certamente mais aceitável do que as referências ao tema feitas na Exortação Apostólica. 
A família atravessa uma crise cultural profunda, como todas as comunidades e vínculos sociais. No caso da família, a fragilidade dos vínculos reveste-se de especial gravidade, porque se trata da célula básica da sociedade, o espaço onde se aprende a conviver na diferença e a pertencer aos outros e onde os pais transmitem a fé aos seus filhos. O matrimónio tende a ser visto como mera forma de gratificação afetiva, que se pode constituir de qualquer maneira e modificar-se de acordo com a sensibilidade de cada um. Mas a contribuição indispensável do matrimónio à sociedade supera o nível da afetividade e o das necessidades ocasionais do casal. (BERGOGLIO, 2013a)

Não há uma única menção às palavras "homossexual", como na entrevista à Civiltà Cattolica, ou "gay", como na entrevista concedida no avião com destino a Roma, em toda a Exortação Apostólica. Deveria se esperar, sem digressões, que esta seria a oportunidade perfeita para abordar o assunto, sobretudo quando tal documento é publicado pouco antes e pouco depois de várias declarações à imprensa quanto à necessidade de uma discussão franca. Contudo, não há confusão ou obscuridade, Bergoglio assevera sua posição no parágrafo supracitado e no seguinte:

O individualismo pós-moderno e globalizado favorece um estilo de vida que debilita o desenvolvimento e a estabilidade dos vínculos entre as pessoas e distorce os vínculos familiares. A ação pastoral deve mostrar ainda melhor que a relação com o nosso Pai exige e incentiva uma comunhão que cura, promove e fortalece os vínculos interpessoais. (BERGOGLIO, 2013a)

A oportunidade para utilizar a terminologia adequada no caso de uma intenção reta de mudança estava na Exortação Apostólica. A questão é que este documento não se trata de um veículo no qual a palavra do pontífice pode viajar até as grandes massas. É um texto longo, de divulgação feita pelo próprio Vaticano, que poucos além de especialistas, teólogos, sociólogos e quem sabe alguns linguistas se preocuparão em analisar, e que dependeria da leitura e do recorte de outros veículos, portais na internet e jornais de grande circulação para ser devidamente divulgado entre o público comum.Caso fosse este o caso, o ethos normalmente praticado diante da imprensa seria posto outra vez em funcionamento. Em vez disso, a questão da união homoafetiva é tratada por meio de referências veladas que falam em terminologia relativamente 
oblíqua, como a solidez da "instituição familiar" nos tempos de hoje, ou o "individualismo pós-moderno" que favoreceria determinado "estilo de vida" que "debilita a estabilidade dos vínculos". Mesmo quando estimulado a aprofundar as questões que clamam por um debate sério e efetivo na Igreja, Bergoglio evita comprometimento, mas não deixa de sentenciar em favor da ordem vigente e contra qualquer possibilidade de mudança, como fica claro neste trecho da entrevista à Civiltà Cattolica:

Não podemos insistir somente sobre questões ligadas ao aborto, ao casamento homossexual e uso dos métodos contraceptivos. Isto não é possível. Eu não falei muito destas coisas e censuraram-me por isso. Mas quando se fala disto, é necessário falar num contexto. De resto, o parecer da Igreja é conhecido e eu sou filho da Igreja, mas não é necessário falar disso continuamente. (BERGOGLIO, 2013b, grifo nosso)

Bergoglio critica os discursos sexistas sobre a participação da mulher na Igreja, mas não vai ordenar mulheres. Fala em acolhida ao gay que ama Jesus, mas está muito distante de reconhecer a união homoafetiva. Muda o tom, não a doutrina, ou seja; o novo papa conservará as pilastras da doutrina católica ao mesmo tempo em que coloca o catolicismo em uma nota mais progressista. A Igreja fica mais simpática com relação a pontos onde dela se exige mais flexibilidade - os excluídos passam a se sentir razoavelmente representados, enquanto sua estrutura segue inalterada. Bergoglio atua como fiador de um mundo ético que serve de miragem de mudança para conservar a relevância e a influência da Igreja Católica.

\section{Considerações finais}

Procuramos desenvolver neste trabalho uma análise da construção de uma nova liderança na Igreja Católica, com a escolha de Jorge Mario Bergoglio ao papado, com base na concepção de ethos e cenografia formulada por Dominique Maingueneau (2008a, 2008b, 2008c, 2008d) sob perspectiva da análise do discurso.

Há uma velha "pérola de vestibular" (nome dado a coisas absurdas e involuntariamente engraçadas escritas em redações de processos de seleção para acesso a universidades), de autor desconhecido, que dita, com acidental sabedoria, que "ultimamente a Igreja Católica vem perdendo muita clientela". 
Uma das explicações para o que faz da Igreja Católica uma nau inabalável sob a arrebentação dos séculos que atravessa está na sua notável habilidade para se adaptar aos tempos, às trocas de poder, às descobertas científicas, às revoluções sociais, isto aliado, é claro, à sede humana pelo conforto existencial e busca de significado neste caos aparente que emperra e torna a mover os pêndulos do universo. Sinais de incongruência, fraqueza, quaisquer fendas notáveis na fronte católica podem abrir espaço para a última visão que se deseja no Vaticano: uma crise de fé. O objetivo de Bergoglio é oposto, unir os cristãos, dialogar com outras religiões, aproximar a Igreja daqueles que ela própria afastou.

Procuramos nos afastar de qualquer debate religioso ou mesmo empreender técnicas de futurólogo para adivinhar as ações e intenções do Papa Francisco para os próximos anos. Limitamo-nos, como o leitor pôde observar, à análise das declarações que julgamos mais relevantes nestes dois primeiros anos de papado para tentar compreender de que modo Bergoglio enfrenta as necessidades dos católicos de hoje, de que modo enfrenta a questão velada colocada pelo próprio conclave que o escolheu (o que significou escolher um papa franciscano e latino-americano?).

O que observamos no momento é a construção em tempo real de uma nova identidade de liderança; apesar de ter sido elevado a uma condição de líder em função do posto que ocupa, Bergoglio trata, nos primeiros momentos de seu papado, de constituir uma ethos de liderança que difere daquele prévio, já estabelecido pela figura do Papa Bento XVI e reforçada por seus antecessores, ou seja: Bergoglio chega a uma posição de liderança que inspira força e legitimidade de modo inato (pela base maciça do símbolo que a sustenta), mas se vê diante da necessidade de desatar alguns pontos-chave dessa figura para estabelecer uma nova liderança, baseada em "novos" valores, mais ajustados aos que os fiéis de hoje da Igreja demandam de seu líder espiritual.

Em termos de resiliência política, é posto e unânime que a Igreja Católica leva o resto do mundo à escola. Para conservar sua posição, é necessário a projeção do ethos adequado, neste caso apoiado cirurgicamente sobre o antimodelo correto. $\mathrm{O}$ Vaticano segue navegando em sua odisseia política com um 
sextante imóbil, é claro; porém, sempre que necessário, sua capacidade de adaptação maleou estruturas inquebrantáveis para conservar esta sua posição que se move, sem dúvida ou digressão, polegadas por século como continentes no oceano.

\section{REFERÊNCIAS}

AMOSSY, Ruth. Da noção retórica de ethos à análise do discurso.In: AMOSSY, Ruth (Org.). Imagens de si no discurso: a construção do ethos. São Paulo: Contexto, 2008b. p. 9-28.

BERGOGLIO, Jorge Mario. Exortação Apostólica "Evangelii Gaudium - A Alegria do Evangelho". 2013a. Disponível em: $<$ http://br.radiovaticana.va/storico/2013/11/26/primeira_ exorta\%C3\%A7\%C3\%A3o_apost\%C3\%B3lica_de_papa_ francisco;_texto_na_\%C3\%ADntegra_de_e/bra-750057>. Acesso em: 17 jan 2015.

. Entrevista ao Papa Francisco por Pe. Antonio Spadaro. 2013b. Disponível em: <http://www.vatican-stg.va/content/ francesco/pt/speeches/2013/september/documents/papafrancesco_20130921_intervista-spadaro.html> Acesso em: 17 jan 2015.

. Papa Francisco fala sobre gays e ganha manchetes pelo mundo. 2013c. Disponível em: <http://g1.globo.com/jornalnacional/noticia/2013/07/papa-francisco-fala-sobre-gays-eganha-manchetes-pelo-mundo.html>. Acesso em: 17 jan 2015.

CHARAUDEAU, Patrick. Discurso político, São Paulo: Editora Contexto, 2006. SP. 2010a.

Linguagem e discurso: modos de organização. São Paulo,

. O discurso propagandista: uma tipologia. In: MACHADO, Ida Lucia; MELLO, Renato. Análises do Discurso Hoje, vol. 3. Rio de Janeiro: Nova Fronteira (Lucerna) 2010b, p.5778. Disponível em: <http://www.patrick-charaudeau.com/Odiscurso-propagandista-uma.html>. Acesso em: 20 jul 2012. 
CORREIO BRAZILIENSE. Distante da ostentação. 2013. Disponível em: < http://www.correiobraziliense.com.br/ app/noticia/especiais/novo-papa/2013/03/16/interna-novopapa,355082/distante-da-ostentacao-papa-francisco-trocaouro-por-simplicidade.shtml > Acesso em: 14 fev 2014.

EGGS, Ekkehard. Ethos aristotélico, convicção e pragmática moderna. In.: AMOSSY, Ruth (Org.). Imagens de si no discurso: a construção do ethos. São Paulo: Contexto, 2008. p. 29-59

EMEDIATO, Wander. Os lugares sociais do discurso e o problema da influência, da regulação e do poder nas práticas discursivas.In.: PROENÇA LARA, Glaucia Muniz; MACHADO, Ida Lucia; EMEDIATO, Wander (Orgs.). Análises do discurso hoje, vol. 1, Rio de Janeiro:Editora Nova Fronteira, 2008, p. 71-91.

GLATZ, Carol. Um papa impossível de enquadrar pode desagradar conservadores e progressistas. Trad. Por Moisés Sbardelotto, 2013. Disponível em: <http://www.ihu.unisinos. br/noticias/522080-um-papa-impossivel-de-enquadrarpode-desagradar-conservadores-e-progressistas $>$. Acesso em: 16 jan 2015.

LAGO, Daniel Siqueira Lopez. O desenvolvimento do conceito de ethos na obra de Dominique Maingueneau. 2008. Disponível em: <http://camarainversa.blogspot.com. br/2008/07/o-desenvolvimento-do-conceito-de-ethos.html>. Acesso em: 18 jul 2014.

MAINGUENEAU, Dominique.A propósito do ethos. In.: MOTTA, Ana Raquel; SALGADO, Luciana. (Orgs.). Ethos discursivo. São Paulo: Editora Contexto, 2008a. p. 11-29.

. Ethos, cenografia, incorporação. In: AMOSSY, Ruth(Org.) Imagens de si no discurso: a construção do ethos. São Paulo: Contexto, 2008b. p. 69-92.

Problemas de ethos. In: POSSENTI, Sírio; SOUZA-ESILVA, Maria Cecília Perez de (Orgs.). Cenas da enunciação. São Paulo: Parábola Editorial, 2008c. p. 55-73. 
Polifonia e cena de enunciação na pregação religiosa. In: PROENÇA LARA, Glaucia Muniz; MACHADO, Ida Lucia; EMEDIATO, Wander (Orgs.). Análises do discurso hoje, Vol. 1. Rio de Janeiro: Editora Nova Fronteira, 2008d. p. 199-218.

TORNIELLI, Andrea; CALABRÓ, Antonietta."Efeito Ratzinger" elegeu Bergoglio papa, dizem jornais. BBC, 2013. Disponível em:<http://www.bbc.co.uk/portuguese/ noticias/2013/03/130315_efeito_ratzinger_papa_bg.shtml>. Acesso em: 17 jan 2015.

\section{Abstract \\ The construction of the ethos in Pope Francis's speeches}

This study aims to investigate the construction of a new leadership in the Catholic Church in the light of the studies on ethos and scenography by Dominique Maingueneau (2008a, 2008b, 2008c, 2008d), the building of the image of itself in the speech. The research will focus on an infographic published on the newspaper Correio Braziliense, in the Pope's interview granted to Father Antonio Spadaro and published in Civiltà Cattolica magazine in September 2013, and in the Apostolic Exhortation Evangelii Gaudium - The Joy of Gospel, published in November 2013. This study seeks to demonstrate that Bergoglio works to buid an ethos of humility and self-denial that finds strength and legitimacy by contrast with the figure of emeritus pope Joseph Ratzinger, his antiguarantor, representative of a set of values in which the current Catholic no longer recognizes leadership. The research also aims to illustrate why the reform promised by supervening of Bergoglio to the papacy hardly correspond to the big reform imagined by the young Catholic community in the world. It will be shown that the most significant change from the first two years of the new Pope is due to the tone of his speech, not real intent to change any aspects of the doctrine.

Keywords: discourse analysis, scenography, ethos. 